\title{
6. Retouch intensity on Quina scrapers at Combe Grenal: A test of the reduction model
}

\author{
Peter Hiscock and Chris Clarkson
}

\section{Introduction}

There have been extensive discussions about whether hominids other than $H$. sapiens had the cognitive capacity to plan and conceptualise elaborate tool forms in advance of use and to transmit those conceptual systems to others. Outside Africa such discussions have been most extensive for questions of what cognitive capacities were possessed by Neanderthals and how their approach to planning and tool use differed from the subsequent $H$. sapiens. A core concern of these questions has been how morphological variation is understood and how that variation can usefully be expressed in classificatory systems that are capable of revealing evolutionary change. Such considerations have been critical in biological debates about the nature of species as well as about specific species boundaries. Similar deliberations are pursued in studies of lithic artefacts, as archaeologists explore how morphological transformations within individual artefacts as well as evolutionary transitions in populations of artefacts, are represented in metrical indices and classifications.

One intensively debated issue in lithic analysis concerns whether conventional practices of analysing retouched flakes by classifying them into a number of tool types is valid or problematic, and whether those types represent tools of distinctly different designs or alternatively arbitrary divisions between objects that display continuous morphological variation. Inferences about these issues have formed the basis of different explanations for the Mousterian facies, and the opposing claims about whether Neanderthals conceived of a large number of tool designs or not (e.g. Bordes, 1972; Binford, 1973; Binford and Binford, 1966; Bourguignon, 1997; Dibble, 1984, 1988b; Dibble and Rolland, 1992; Rolland and Dibble, 1990; Hiscock and Attenbrow, 2005; Hiscock et al., 2009; Holdaway et al., 1996; Mellars, 1996; Turq, 1992, 2000). Debates about the nature of economy, technology and cognition in ancient hominids are both significant and exciting, but they rest on the accuracy and clarity of depictions of artefact patterning and the meaning of morphological and technological diversity. 
Although much has been written on the characterisation of retouched flake variability in Middle Palaeolithic assemblages, key aspects of the archaeological patterns remain unresolved.

In recent decades, two different hypotheses have competed as the best explanation for the variability observed in Mousterian implements from the Dordogne. One model advocates the primacy of retouch intensity in models explaining morphological diversity in ancient tools, with some researchers arguing this is the sole significant factor creating typological variation. The second model argues that intensity of retouch is only one of many factors creating variation and that others are often more significant. In this chapter we test these competing models by presenting a detailed, quantitative analysis of the relationship between different types of Quina scrapers and the extent of retouching that they have undergone in one level of Combe Grenal.

\section{The question of Quina scrapers and reduction}

A well-known model for Middle Palaeolithic scraper reduction was proposed by Harold Dibble (1984, 1987a, 1987b, 1988a, 1988b, 1995). He hypothesised the transformation of scrapers from one typological class to another as they received additional reduction. Dibble argued that extent of reduction was the key factor causing differences between four implement classes with retouch onto their dorsal surface: (1) single-edged side scrapers with retouch on one lateral margin (Bordes types 9-11); (2) double scrapers with two separate retouched edges (Bordes types 12-17); (3) convergent scrapers which have two retouched edges that touch (Bordes types 8, 18-21); and (4) transverse scrapers which have retouch across the distal end of the flake (Bordes types 22-24). Examples of these classes are provided in Figure 6.1. Dibble interpreted these four kinds of implement as a result of different amounts of reduction, in which all specimens began as single scrapers, but with additional retouching were either transformed into transverse scrapers or alternatively into double and eventually convergent scrapers. This model, schematically shown in Figure 6.2, notionally positions each of these four classes along a continuum of greater or lesser amounts of retouch, and reveals the proposition that there were two branches along which individual scrapers could travel from the same starting point. Dibble (1988b: 49; 1995: 319) suggested that those individual single scrapers that were further retouched were either worked at the distal end to become transverse forms or on the second lateral margin to become double/convergent implements. He suggested that the sequence followed by any individual specimen may have depended on the shape of the flake, with short/broad flakes being worked into transverse scrapers while longer, narrow flakes were retouched laterally to become double and convergent scrapers. However, Dibble (1995: 319) argued 
that much of the variation between implement classes, and specifically the morphology diagnostic of different types, was a product of differences in the level of retouching and the length of time they had been used and maintained: single scrapers had undergone little retouching while both transverse and convergent scrapers were more intensively retouched. In a series of papers he argued that the smaller average size of convergent and transverse scrapers, both in absolute terms and relative to their platform size, was evidence that this model was correct for Quina assemblages from southwest France and elsewhere.

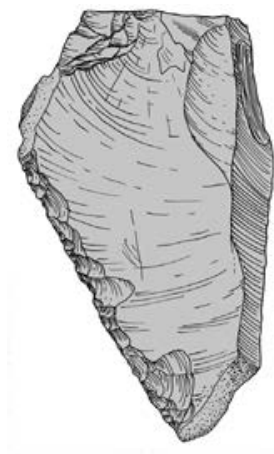

A) Single Scraper

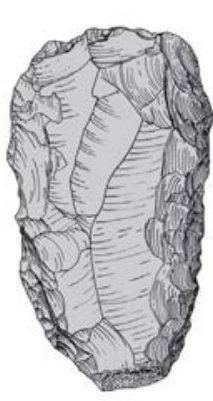

B) Double Scraper

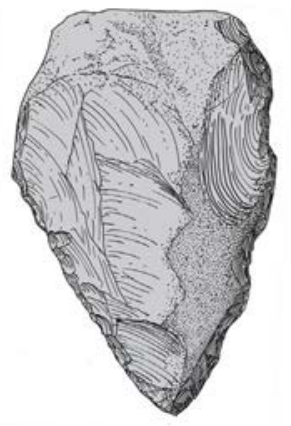

C) Convergent Scraper

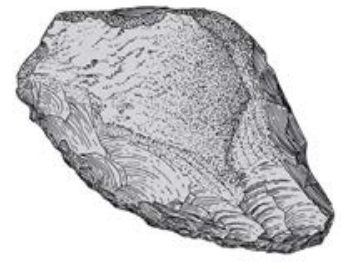

D) Transverse Scraper

Figure 6.1: Examples of specimens classified into each of the four scraper classes: A) Single scraper, B) Double scraper, C) Convergent scraper, and D) Transverse scraper. All specimens are from Combe Grenal, Layer 21.

Source: Authors' original work depicting artefacts from Combe General.

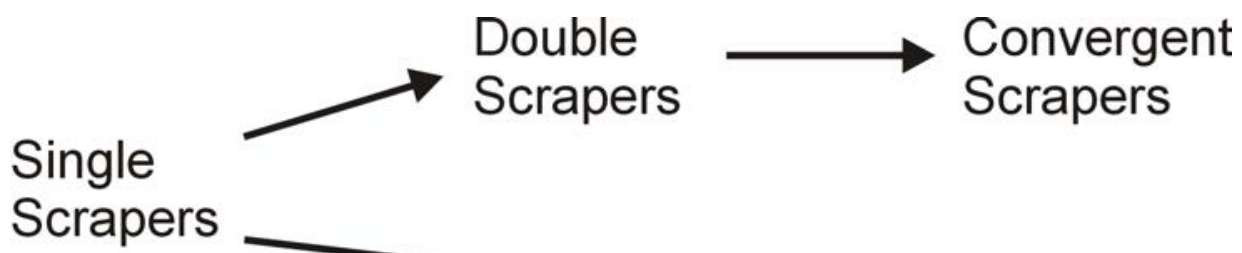

Transverse Scrapers Low $\quad$ Amount of mass removed by retouching High

Figure 6.2: Diagrammatic representation of the staged reduction model proposed by Dibble. 
This conclusion implies and necessitates particular interpretations of Mousterian variability. For example, although Dibble believed that the typology of Bordes still had value, he argued that the different types were a continuum created by differing extents of edge resharpening and that the implement classes therefore represented coherent stages in the continuum of retouch (Dibble and Rolland 1992: 11). Consequently Dibble (1988b: 52) stated that traditional implement types were best employed as a proxy for the extent of tool maintenance/ resharpening in archaeological assemblages.

One interpretation that has followed from Dibble's model of flake retouching is that differences between implement types and industries reflect differences in the intensity of tool use (and by implication the nature of land use); they do not reflect mental constructions of Neanderthals, nor do they reveal specific differences in design or function. For instance, Dibble and Rolland (1992: 17) argued that the production of industries dominated by convergent or transverse scrapers were a consequence of economic practices that encouraged more intensive tool use, such as the intensive maintenance of tools during cold palaeo-climatic phases in which there were long winter residence and patterns of settlement based on the interception of migratory herds, situations in which provisioning of stone for tools could have proved difficult. They contrast this with the contexts of industries dominated by side scrapers (and denticulates), which they hypothesised resulted from less intensive tool and site use that occurred under milder climatic phases in which Neanderthal economy was focused on the pursuit of dispersed, mobile game. The value of these kinds of interpretations depends on the veracity of the characterisation of traditional implement types as comparable units primarily reflecting differences in the extent of tool resharpening.

A number of commentaries and further studies have followed the publication of Dibble's model, many supporting his argument of the value of traditional implement types for studies of the extent of implement reduction (e.g. Gordon, 1993; Holdaway et al., 1996). However, significant reconsiderations of the factors involved in implement creation have been offered. The most potent is the proposition that the extent of retouching is not a function of the intensity of edge maintenance alone, but was often a reflection of the size and morphology of the flake to which retouch had been applied. For instance, Dibble (1991: 266), Gordon (1993: 211), and Holdaway and others (1996) all argued that larger flakes typically had greater potential for edge resharpening, and consequently in extensively reduced assemblages those larger specimens received more retouching than smaller ones. One result of the continued reduction of larger specimens, but not smaller ones, is that extensively retouched flakes were sometimes still larger when discarded than less extensively retouched ones made on smaller flakes (Dibble, 1991). While this proposition has been applied 
to notched types (e.g. Holdaway et al., 1996; Hiscock and Clarkson, 2007), its implications for the interpretation of other implement types and for the value of typology as a measure of the extent of retouching has received less attention. One obvious implication is that the amount of retouching applied to a specimen cannot be judged by its size (Dibble, 1991), a realisation that encouraged the development and growth of several methods for measuring retouch intensity on Middle Palaeolithic tools (see Dibble, 1995; Hiscock and Clarkson, 2005). However, the existence of a strong relationship between flake form and retouch has been argued to create problems for the interpretation of implement types as reduction stages.

For example, if retouching is a response to flake morphology and there is variation in the size and shape of flakes being retouched, an almost inevitable reality in most prehistoric contexts, then the amount of mass removed during retouching may vary substantially between specimens assigned to any implement type. This appears to be the case in the data presented by Dibble (1987b: 113) for the La Quina scrapers, which display extraordinarily high levels of intra-type variability in reduction measures, such as flake area/ platform area ratios which show coefficients of variation of $125 \%$ for single scrapers, $49 \%$ for double scrapers, $91 \%$ for convergent scrapers and $182 \%$ for transverse scrapers. Although Dibble still found statistically significant differences between the means of these four implement classes, the measured variability probably reflects very great differences in the amount of retouching between specimens in a single implement class. In such circumstances the value of conventional types as units measuring the extent of reduction may be questioned, and Hiscock (1994) argued that analysts would be better able to discuss differences in amounts of retouching if they focused on measuring the manufacture of individual specimens rather than merely the contrast between types (also Hiscock and Clarkson, 2005; Clarkson and Hiscock, 2008).

Furthermore, many researchers have argued that intensity of retouch is not the most important factor affecting the form of retouched flakes. For instance, Kuhn (1992) has argued that if flake form played a significant role in determining the position and amount of retouch on each object then typological composition is not principally affected by the intensity of tool use and so industrial variation may not directly correspond to different patterns of settlement and mobility. Instead, Kuhn argues the typological composition of an assemblage would reflect the size and shape of available flakes, which in turn would reflect the form and availability of raw material and the tactics of core reduction. While raw material procurement and core reduction may also be linked to economic and settlement patterns, the connection with the abundance of each implement type would be remote and indistinct. While Kuhn did not deny the proposition that intensity of retouch may be an indicator of settlement/mobility systems, he argued that 
types are not reliable indicators of intensity of retouch, and that archaeologists will require dedicated measurements of retouch intensity prior to developing inferences about the land-use from lithic artefacts.

Long-term archaeological research in southwest France has yielded much evidence for the complex articulation of core reduction systems and the patterns of retouched tools made on the flakes produced in those systems (e.g. Bisson, 2001; Bourguignon, 1997; Bourguignon et al., 2004; Thiébaut, 2003; Turq, 2000; Verjux, 1988; Verjux and Rousseau, 1986), reinforcing the possibility that flake form may have an important role in the construction of morphological diversity amongst Mousterian implements. Many discussions of flake-retouch relationships have posited a simple relationship between flake elongation and the position of retouch, suggesting that long flakes were often retouched on their lateral margins, whereas short, wide flakes were often worked at the distal end (e.g. Bordes, 1961: 806, 1968: 101; Turq, 1989; Mellars, 1992). A number of researchers have argued that the flakes on which single and transverse scrapers were made are very different, and that regular production, and/or selection, of flakes with particular characteristics was a significant factor in the formation of the typological composition of any assemblage (e.g. Turq, 1989, 1992). As a consequence, Turq (1989) argued that there were clear morphological discontinuities in the form of single and transverse scrapers in the Dordogne, evidence that would not be conformable with Dibble's reduction hypothesis. The hypothesised connection of flake form and systems of core reduction has also been argued to be evidence for deliberate and planned acts of selection/ production (e.g. Boëda, 1988; Turq, 1989, 1992).

Some models of the way the morphology of flakes strongly influenced the nature, and typological category of implements have hypothesised complex interactions between multiple characteristics that affected the nature of retouching. An example is Alain Turq's proposal that scrapers in Quina industries reflected a regular pattern of flake selection and retouching. He suggested that transverse scrapers, unlike single side scrapers, were made on flakes that were thick relative to their length and ventral surface area; a proposition that would account for differences between types in the relationship of platform and ventral areas, which Dibble (1984, 1987a, 1987b, 1995) had employed as evidence for different degrees of reduction. Furthermore, Turq argues that scrapers were typically made on flakes with asymmetrical cross-sections and retouch was located on the flake margin furthest from the maximum thickness (Turq, 1992: 75). In a diagram, presented here as Figure 6.3, Turq (1992: 77) implied that the potential for resharpening was related to the asymmetry of each flake selected for retouching, with symmetrical ones having little mass removed before steep retouching came close to reaching the thickest part of the flake while asymmetrical flakes could have considerably more mass removed 
through retouching before reaching the same state. This proposition linked variation in scraper morphology with flake morphology as well as extent of reduction, implying that flake shape and selection were the proximate factors creating variation in both the location/orientation of retouch and the amount of mass removed by retouching on different specimens, and consequently the typological category into which each specimen was placed. Turq's model not only contrasts with Dibble's in the emphasis given to flake form rather than extent of reduction, but also implies that there may be a great deal of difference in the extent of reduction of specimens with similar cross-sections and placed in the same typological category.

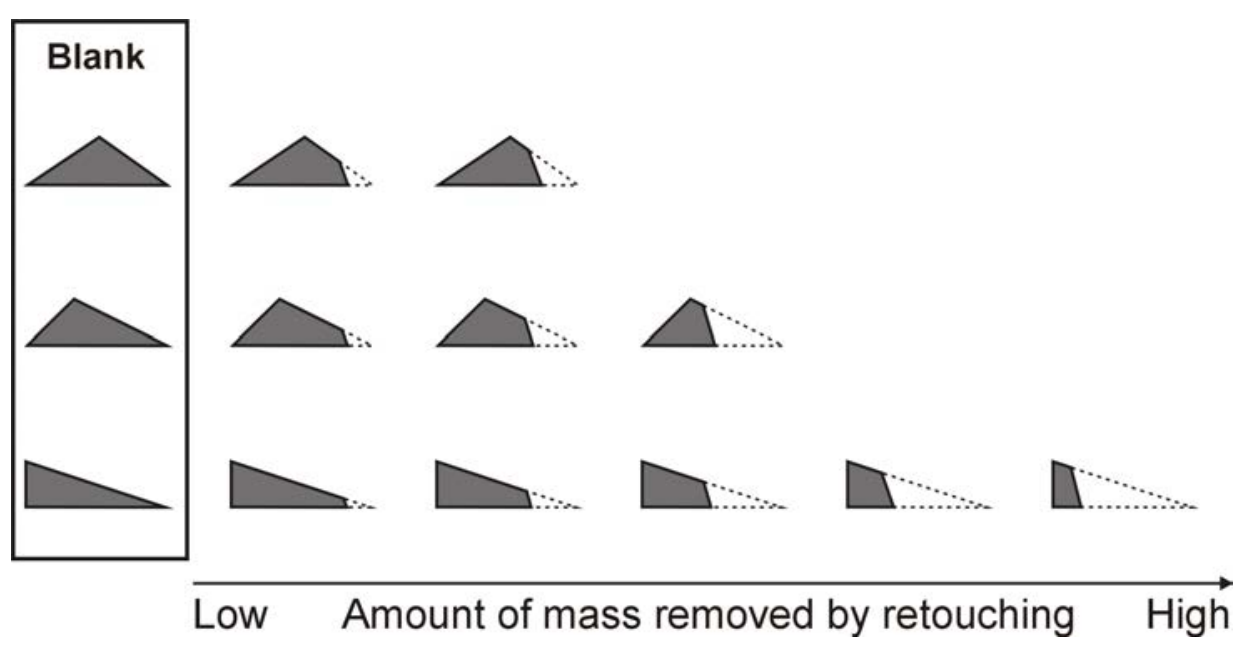

Figure 6.3: Notional illustration of the relationship of blank cross-section and extent of reduction for dorsally retouched Quina scrapers.

Source: After Turq (1992: Figure 6.2).

Considered in this way, the distinctions between two different models of Quina scraper variability are clear. On the one hand Dibble's 'scraper reduction model', posits a single branching scheme and asserts that traditional typological categories represent different points/stages along a continuum of greater or lesser amounts of retouch. The frequency of specimens in each type may therefore be used as a proxy for the intensity of reduction that an assemblage has undergone. From this perspective intensity of reduction is the primary cause of typological variation, and although differences in flake morphology exist, their effect on typological variation is minimal. Consequently typological diversity through time and space can be directly interpreted as a result of access to raw material and settlement/economic activities. On the other hand, what Hiscock and Clarkson (2008) have called the 'blank-retouch interaction hypothesis' proposes that traditional typological categories represent complex patterns of 
morphological variation created by several factors, particularly differences in the distribution and intensity of retouch in response to flake form. Distinctions between conventional implement types may therefore have little coherent covariation with intensity of retouch, and should not necessarily be treated as representing different points along a reduction continuum. This hypothesis implies that the frequency of specimens in each type may not be a reliable indicator of the intensity of retouching that an assemblage has undergone, and that typological diversity through time and space is difficult to directly interpret in terms of settlement/economic activities. Instead, this hypothesis asserts that Borde's typology reflects morphological patterns created by a constellation of factors including flake morphology, material cost, tool design, as well as amount of uselife/resharpening, and that the resulting typological patterns are not necessarily sensitive to variation in the intensity of retouch.

Our goal here is to examine the applicability of these two opposing models to one Quina assemblage, recovered from Layer 21 in Combe Grenal. Although these models predict different behavioural processes, they both invoke extent of retouching as a mechanism constructing morphological variation; the two models differ in the way retouching is articulated to other technological and economic factors. We emphasise that there is no reason to expect that one will inevitably be the most appropriate in all situations. It is possible for the 'reduction hypothesis' to be correct for some assemblages and the 'blankretouch interaction hypothesis' to be correct for others. In this way these opposing models are not competitors in a search for a universal truth but are actually expressions of the variable operation of multiple factors that may have created morphological variation in Mousterian implements. Consequently our examination of these two models for Layer 21 at Combe Grenal is not a test of the general veracity of either model, but actually an assessment of what kinds of processes were operating in the Neanderthal technological system in the Perigord Noir at the time that layer formed.

\section{Our approach to measuring the extent of retouching}

Our sample of artefacts comes from Combe Grenal, excavated by François Bordes (1972) and now held at the Musèe National de Prèhistoire des Eyzies. The following analysis uses measurements of complete dorsally retouched flakes from Layer 21, a Quina level. Technological cores and unretouched flakes, broken specimens, and a small number of burins, end scrapers, Mousterian points and a truncated-faceted piece were excluded from the analysis. For this paper our sample consists of 306 objects, representing all specimens in each of 
the major typological categories: single scrapers $(\mathrm{N}=172)$, double scrapers $(\mathrm{N}$ $=28)$, convergent scrapers $(\mathrm{N}=40)$, transverse scrapers $(\mathrm{N}=66)$. The number of specimens in each of the Bordes type classes used in our analysis is listed in Table 6.1.

Table 6.1: Sample of complete retouched flakes from Layer 21 used in this analysis, presented by implement type.

\begin{tabular}{|l|r|}
\hline \multicolumn{1}{|c|}{ Implement types } & N \\
\hline Single & 50 \\
\hline 9 Single straight scraper & 112 \\
\hline 10 Single convex scraper & 10 \\
\hline 11 Single concave scraper & 14 \\
\hline Double & 7 \\
\hline 12 Double straight scraper & 2 \\
\hline 13 Double straight-convex scraper & 4 \\
\hline 14 Double straight-concave scraper & 2 \\
\hline 15 Double convex scraper & 3 \\
\hline 16 Double concave scraper & 5 \\
\hline Convergent & 30 \\
\hline 8 Limace & 14 \\
\hline 18 Straight convergent scraper & 49 \\
\hline 19 Convex convergent scraper & \\
\hline 21 Dejete scraper & \\
\hline Transverse & \\
\hline 22 Straight transverse scraper & \\
\hline 23 Convex transverse scraper & \\
\hline 24 Concave transverse scraper & \\
\hline
\end{tabular}

Source: Author's data.

Our analysis of these implements employs two measures of the position of retouching on each specimen and the amount of mass removed through retouching (Figure 6.4). The first is a version of the Geometric index of unifacial reduction (GIUR), a measure we have experimentally verified (Hiscock and Clarkson, 2005, 2009; Clarkson and Hiscock, 2008). Our experiments showed that scar height ratios, taken at multiple points around a retouched flake, yield an average GIUR value which has a non-linear relationship with the mass removed by retouching (Hiscock and Clarkson 2005: 1019). Experimental retouching of flakes demonstrated that there was a strong log-linear relationship between the calculated Kuhn GIUR and the percentage of original flake weight that has been lost (Figure 6.5). This relationship appears to hold irrespective of whether retouching is applied to the lateral or distal margin (Hiscock and Clarkson, 
2005), or to one or more than one edge (Clarkson and Hiscock, 2008; Hiscock and Clarkson, 2009). For instance, when we experimentally retouched flakes on one lateral margin, producing items similar to single side scrapers, there was a strong positive relationship between the index value and the mass removed by retouching $\left(\mathrm{r}=0.933, \mathrm{r}^{2}=0.871\right)$. When we experimentally retouched flakes on two lateral margins the Kuhn GIUR was still strongly and significantly correlated with the proportion of mass lost from each flake $\left(r=0.88, r^{2}=0.778\right)$. We have argued elsewhere that while variations in the GIUR/mass-lost relationship occurred as a consequence of differences in the shape and size of flake blanks, a strong relationship exists for most flakes that are dorsally retouched, and consequently we take the Kuhn GIUR to be a reliable measure of the extent of dorsal, unifacial retouch in most instances, including the specimens discussed in this analysis, irrespective of the nature of the flake (Hiscock and Clarkson, 2005: 1022). Furthermore, the high coefficient of determination $\left(\mathrm{r}^{2}\right)$ allows us to use the regression line and 95\% confidence intervals shown in Figure 6.5 to estimate the approximate amount of mass removed during retouching.

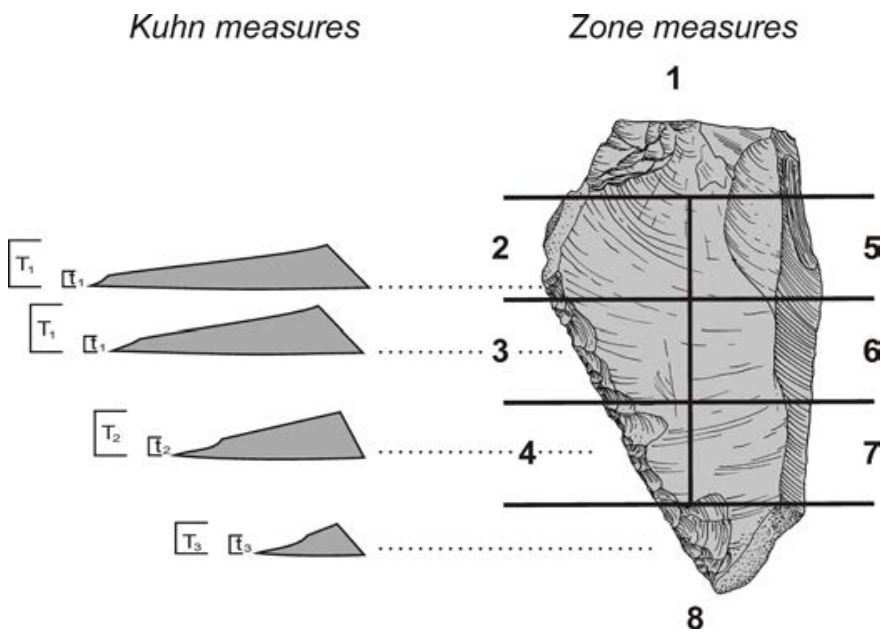

Figure 6.4: Illustration of the measurements of reduction used: multiple values of Kuhn's (1990) unifacial reduction index and a count of the number of zones which have been retouched.

Source: Hiscock and Clarkson (2005). 


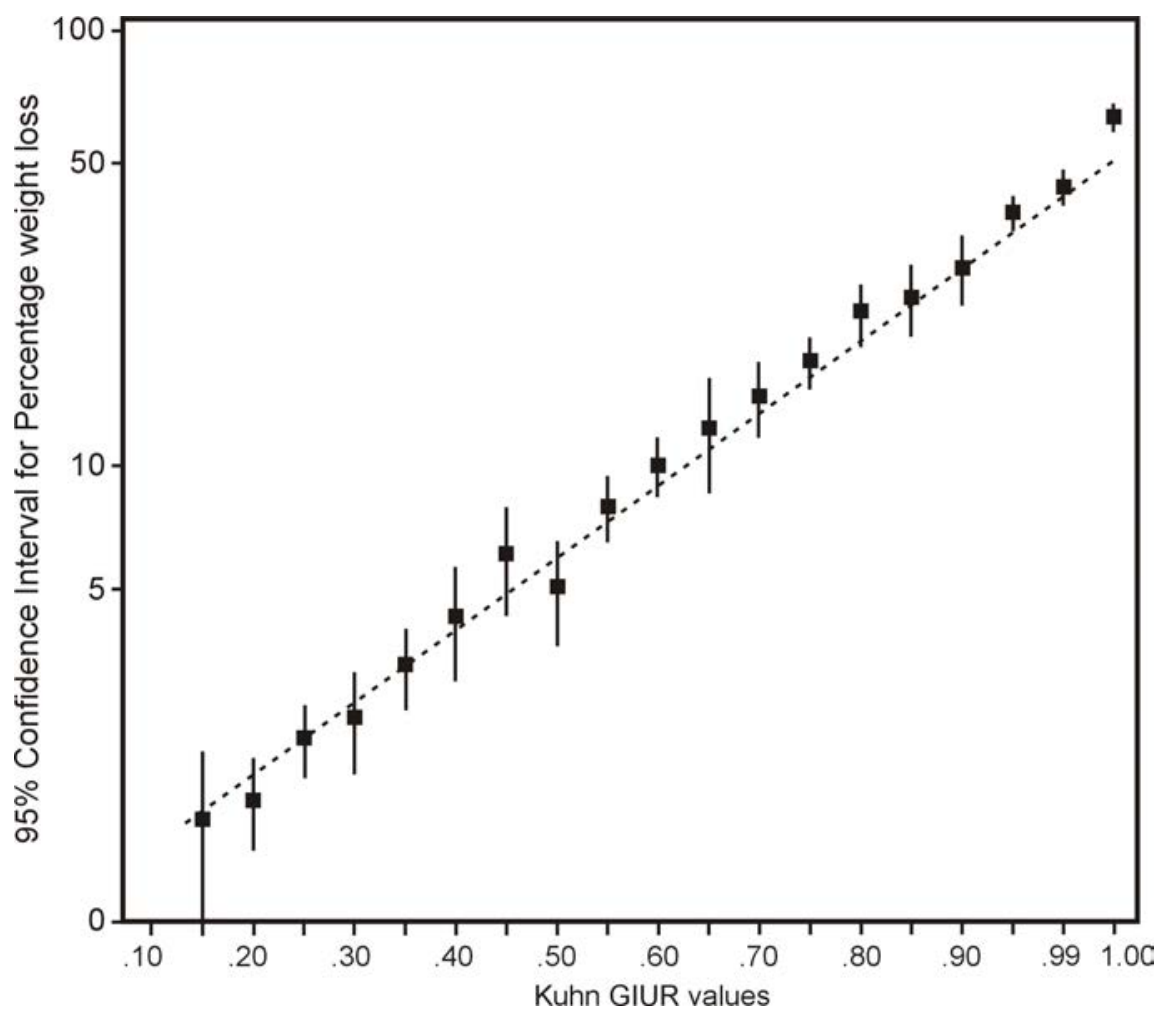

Figure 6.5: Relationship between Kuhn GIUR (as 0.05 intervals) and the percentage of original flake mass lost through retouching (shown with 95\% confidence intervals) in the experimental dataset (Hiscock and Clarkson 2005). Broken line is the regression line $\left(r=0.933, r^{2}=0.871\right)$ published by Hiscock and Clarkson (2009).

Source: Hiscock and Clarkson (2009).

A second measure of retouching was the distribution of retouch on the margins of each flake. This measure provides an indication of the lateral expansion of retouching around the specimen; complementing the GIUR, which measures how far retouch has penetrated into the centre of a flake (Hiscock and Attenbrow, 2005: 59). This 'Retouched zone index' was obtained by observing which of eight zones, illustrated in Figure 6.4, were retouched. The zones were defined in terms of five equal divisions of the percussion length, but with the left and right margins being separated to create eight locations (proximal, distal, three zones on the right margin and three on the left). The face on which scars occurred was not relevant for this measure, giving retouched flakes values between 1 and 8 zones. This recording system was not only used to measure the amount of retouch around the flake margin, but also served as a way to compare the location of retouch on different specimens. 
Other measures of flake retouching, such as Clarkson's (2002) invasiveness index or Holdaway, McPherron and Roth's (1996) surface area/platform thickness ratio were considered to be of lesser value on the steeply, unifacially retouched flakes in our sample and are not presented here. Although we have previously expressed doubt about the sensitivity of Dibble's (1987) surface area/platform area ratio as a measure of reduction we have calculated this below as a comparison to published data that has been used to discuss models of Quina retouch.

\section{The extent of retouching and implications for reduction}

With these measurements of the amount of retouching, we are able to evaluate whether the different implement categories (single, double, convergent, transverse scrapers) actually represent clusters of specimens that have been reduced to different extents, as hypothesised by Dibble. Descriptive statistics for the reduction indices in our sample, presented in Table 6.2, show a pattern somewhat similar to that reported by Dibble (1987: 113) for the La Quina site, and which he used in support of his reduction model. For instance, the mean surface area/platform area values are higher for single scrapers than double and convergent ones, and transverse scrapers display the smallest mean; with the means being very similar to those Dibble found at La Quina. This offers support for the proposition that, on average, single scrapers were less reduced that the other three scraper categories. Average values for the Kuhn GIUR and retouched zone index could also be used to suggest that single scrapers were on average less reduced than double or convergent scrapers; giving support to the idea of a single-double-convergent sequence of scraper transformations in Layer 21. ANOVA treatment of our data reveals statistically significant differences between the implement classes in the Kuhn GIUR $(\mathrm{F}=5.485$, d.f. $=4, \mathrm{p}=0.001$, with the index broken into five groups: $0.01-0.19,0.20-0.39,0.40-0.59,0.60-0.79$, and $0.8-1.0)$ and in the retouched zone index $(\mathrm{F}=10.112$, d.f. $=7, \mathrm{p}<0.001)$; but not in the surface area/platform area ratio $(\mathrm{F}=0.295$, d.f. $=4, \mathrm{p}=0.881)$, with the index broken into five groups: 0.01-4.99, 5-9.99, 10-49.99, 50-99.99, and $>100$. These statistics all indicate that there is patterned variation in the central tendencies for retouching intensity between the four classes of implement.

However, the relationship of transverse and single scrapers is not consistent with the predictions of Dibble's reduction model. Differences in mean Kuhn GIUR alone $(\mathrm{t}=3.239$, d.f. $=236, \mathrm{p}=0.001)$ conform with the predictions of Dibble's (1987) model, although the question of how to interpret the large variation in each class is discussed below. Average surface area / platform area values were not significantly different for transverse and single scrapers $(t=-0.892$, d.f. $=208$, 
$\mathrm{p}=0.373)$, and the retouched zone index indicates that transverse scrapers have significantly less extensively retouched margins than single scrapers $(\mathrm{t}=-4.185$, d.f. $=97.8, \mathrm{p}<0.001$ ), a finding that is not compatible with Dibble's model in which the addition of distal retouch converted single scrapers into transverse ones. These statistics imply a difference between single and transverse scrapers in intensity and location of reduction, but not necessarily as sequential stages as Dibble argued in model of his single-transverse sequences.

Table 6.2: Descriptive statistics for the Kuhn GIUR, Retouched zone index, and surface area/platform area ratio of four implement classes in Layer 21 of Combe Grenal.

\begin{tabular}{|c|c|c|c|}
\hline & Kuhn GIUR & $\begin{array}{l}\text { Retouched zone } \\
\text { index }\end{array}$ & $\begin{array}{c}\text { Surface area/platform } \\
\text { area }\end{array}$ \\
\hline $\begin{array}{l}\text { Single } \\
(N=150)\end{array}$ & $\begin{array}{r}0.49 \pm 0.20 \\
0.15-1.00\end{array}$ & $\begin{array}{r}4.05 \pm 1.42 \\
1-8\end{array}$ & $\begin{array}{r}14.59 \pm 31.10 \\
1.0-297.4\end{array}$ \\
\hline $\begin{array}{l}\text { Double } \\
(N=23)\end{array}$ & $\begin{array}{r}0.60 \pm 0.16 \\
0.31-0.91\end{array}$ & $\begin{array}{r}6.61 \pm 1.12 \\
2-8\end{array}$ & $\begin{array}{r}11.86 \pm 7.20 \\
2.9-31.2\end{array}$ \\
\hline $\begin{array}{l}\text { Convergent } \\
(\mathrm{N}=31)\end{array}$ & $\begin{array}{r}0.61 \pm 0.16 \\
0.26-0.98\end{array}$ & $\begin{array}{r}6.26 \pm 1.59 \\
2-8\end{array}$ & $\begin{array}{r}11.81 \pm 20.32 \\
1.2-105.8\end{array}$ \\
\hline $\begin{array}{l}\text { Transverse } \\
(\mathrm{N}=60)\end{array}$ & $\begin{array}{r}0.61 \pm 0.21 \\
0.17-1.00\end{array}$ & $\begin{array}{r}2.97 \pm 1.78 \\
1-7\end{array}$ & $\begin{array}{r}10.79 \pm 17.78 \\
0.5-102.7\end{array}$ \\
\hline
\end{tabular}

Note: Top line is mean and standard deviation, lower line is the minimum and maximum value.

Source: Authors' calculation.

These data document differences between these implement classes in the average degree of reduction, but such differences may not constitute evidence of the transformation of specimens from one implement class to another. An examination of the variation found within each implement class reveals that the assemblage from Layer 21 does not conform to Dibble's reduction model. Each of implement class displays high levels of variation in the reduction measures. In particular single and transverse scrapers show large ranges of reduction indices. For example, on single scrapers the coefficient of variation for Kuhn GIUR is $41 \%$ and for the retouched zone index it is 35\%, while transverse scrapers have a coefficient of variation for Kuhn GIUR of $34 \%$ and for the retouched zone index $60 \%$. This indicates that each of those typological groupings contain specimens with very different levels of retouch. Using the Kuhn GIUR to estimate the proportion of original flake mass removed through retouching shows that single scrapers lost $2-66 \%$ of their weight, double scrapers 3-30\%, convergent scrapers $5-35 \%$, and transverse scrapers $4-66 \%$ of blank weight. When intensity of reduction is expressed in this way it is clear that Dibble's reduction models do not account for all of the specimens in Layer 21. For instance, some single scrapers are extensively reduced; some more than twice as reduced as any 
double or convergent scrapers. The existence of single scrapers with very high amounts of mass removed through retouching, and that were not converted into double or convergent forms, demonstrates that specimens typologically classified as single scrapers were not all 'early stage', with only little retouch. Conversely the existence of double, convergent and transverse scrapers with less than $5-10 \%$ of mass removed through retouching, representing the initial creation of the edge and perhaps one resharpening episode, demonstrates that such forms were not always more heavily retouched than single scrapers. Similarly, many transverse scrapers were not noticeably more reduced than many single scrapers, as might be expected if they were created at a later stage. However, other transverse scrapers have been extensively retouched, probably losing more than $50 \%$ of their original mass. This illustrates that the intensity of reduction within each implement class is highly variable. Further evidence for this within class variation in retouching intensity, and its implications, is provided in the following sections.

\section{Single Scrapers}

The striking characteristic of single scrapers in Layer 21, besides the strong pattern of retouch positioned on one lateral margin, is the great difference in the extent of reduction that different specimens had undergone. Some of the variation in the extent of retouching is displayed by the retouched zone index. The majority of single scrapers were retouched along much of one lateral margin, resulting in retouch scars in four or five zones (Figure 6.6). However, a few specimens had retouch restricted to a small portion of the lateral margin, only one or two zones; and some specimens also had small occurrences of retouch elsewhere on the flake, in more than five zones. The distribution of retouch around the flake margin was clearly related to blank characteristics, such as edge angle, cross-section and distribution of cortex.

Another dimension of retouch intensity, measured by the Kuhn GIUR, also displays extreme variation. Figure 6.6 shows a histogram of the abundance of specimens with different levels of the Kuhn GIUR. Almost $20 \%$ of single scrapers had a GIUR less than 0.3 , equating to less than about $5 \%$ of the original flake mass removed by retouching. Most single scrapers had GIUR values of $0.3-$ 0.8 , representing about $5-20 \%$ of mass loss. Some single scrapers, about $10 \%$ of those in Layer 21, had GIUR values greater than 0.8 , representing retouch that removed approximately $30 \%$ to more than $60 \%$ of the original mass. While conversion of GIUR values to mass lost through retouching in this way is only an estimate, it expresses the large differences in retouch intensity that are evident on different single scrapers. 

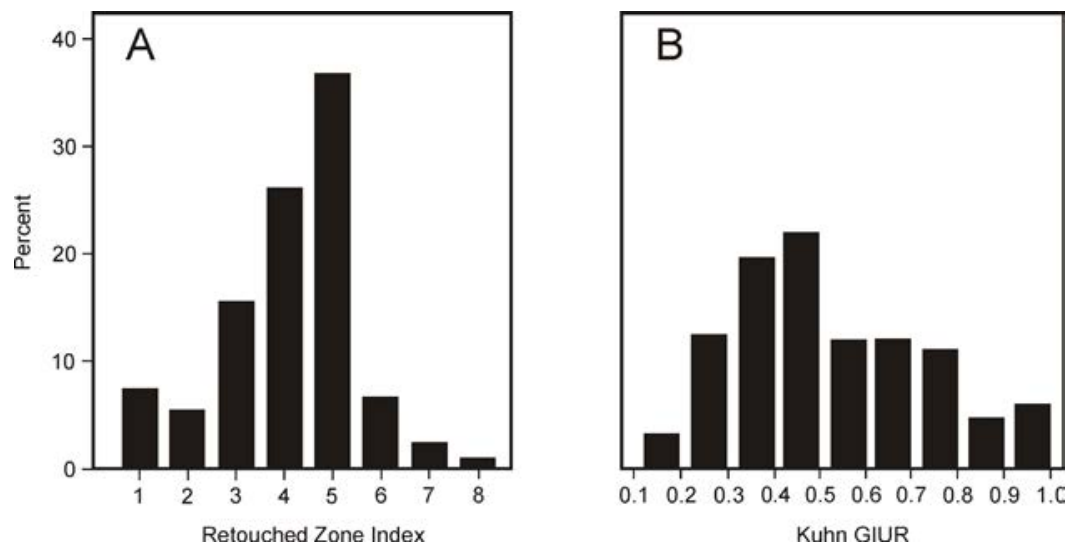

Figure 6.6: Histogram of the Kuhn GIUR values for single scrapers from Layer 21.

Source: Authors' calculations.

Single scrapers
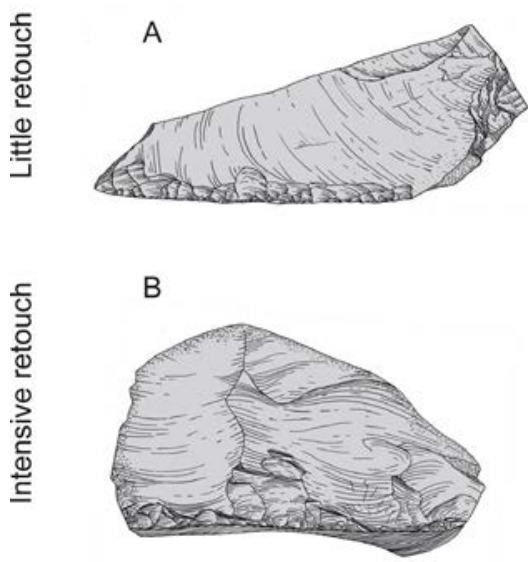

Transverse scrapers

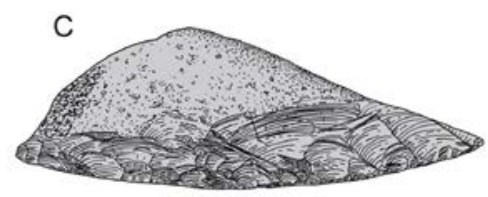

D

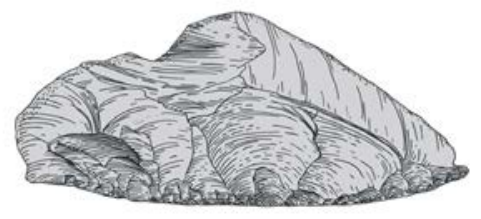

Figure 6.7: Examples of different levels of reduction on scrapers: A-B = Single scrapers, $C-D=$ Transverse scrapers; $A$ and $C=$ little mass removed, $B$ and $D=$ extensive mass removed. $A=$ Single scraper with a Kuhn index of $0.44 ; B=$ Single scraper with a GIUR index of 1.00 . $C=$ Transverse scraper with a Kuhn index of 0.56; $D=$ Transverse scraper with a Kuhn index of 0.91 .

Source: Authors' calculations.

Differences in the extent of retouching on single scrapers are illustrated in Figure 6.7, which presents two single scrapers: one with a small amount of material removed by retouching and the other with a large amount. The first specimen is a long flake with a series of small retouch scars, mostly about $3 \mathrm{~mm}$ 
long, on three zones of the left lateral margin (Figure 6.7A). The Kuhn GIUR of 0.44 recorded for this specimen, in association with low unretouched edge angles of $20-25^{\circ}$ in the retouched zones, is consistent with less than $5-10 \%$ of the original flake mass being removed by retouching. The other specimen (Figure 6.7B) was the remnant of a wide, thick flake which has been extensively reduced through the removal of large flakes from along the entire right lateral margin (retouch in five zones). This specimen has a GIUR of 1.00, with the retouch scars having removed the thickest part of the flake; a pattern consistent with the removal of approximately $45-65 \%$ or more of the original flake mass by retouching. Together these two illustrations exemplify the different levels of reduction present amongst single scrapers in Layer 21 .

In conjunction with the statistics, these specimens demonstrate that some single scrapers in Layer 21 were minimally retouched while others were heavily retouched. The heavily retouched specimens, as indicated by the GIUR, typically have retouch scars only on one lateral margin and had always been a single scraper throughout the retouching process. The evidence from such specimens shows that some single scrapers became very intensively retouched but that the level of reduction did not alter their typological status.

\section{Double and convergent scrapers}

Double and convergent scrapers are almost certainly made from single scrapers that had appropriate sizes and shapes, since one retouched margin must have been created before the other. The higher mean and minimum GIUR values for both classes, in comparison to single scrapers, are consistent with that interpretation, but do not prove it. However, the evidence for Layer 21 does not conform to Dibble's proposed single-double-convergent sequence of type stages. We have already discussed the observation that single scrapers were sometimes very intensively retouched and so specimens in that typological class do not always represent a stage of minimal reduction. This demonstrates that double/ convergent scrapers are not always highly retouched and single scrapers were not always minimally retouched.

Furthermore, in the collection from Layer 21 there is no difference in the intensity of reduction of the double and convergent scrapers. There is no significant difference between these two classes for any measure of retouching intensity: Kuhn GIUR ( $\mathrm{t}=-0.566$, d.f. $=66, \mathrm{p}=0.573)$, retouched zone index $(\mathrm{t}=0.995$, d.f. $=66, \mathrm{p}=0.323)$, and platform surface/platform area index $(\mathrm{t}=-0.010$, d.f. $=$ $52, \mathrm{p}=0.992)$. The ranges and distribution of values are also comparable for these measures; evidence that indicates specimens in both groups show varied but comparable levels of retouch intensity. Since convergent scrapers in this 
assemblage are not more reduced than double scrapers the notion that double scrapers were regularly converted into convergent scrapers is unlikely to be correct.

Instead, it seems likely that double and convergent scrapers are made on different kinds of flakes. A number of features of the flake are preserved on these retouched specimens and show statistically significant differences between the two classes. For example, the mean platform thickness of double scrapers is significantly lower than for convergent scrapers $(\mathrm{t}=-3.318$, d.f. $=$ $49, \mathrm{p}=0.002$ ). This evidence indicates that the relative positioning of retouched edges in double and convergent scrapers, leading them to be assigned to different types, may reflect the knapper's response to dissimilarities in flake form rather than extent of retouch. Hence, it is possible to conclude that more specimens classified as double and convergent scrapers were reworked single scrapers, but that many of the convergent scrapers are not more intensively retouched than double scrapers, the typological distinction largely reflects the influence of the different flake blanks from which they were made.

\section{Transverse scrapers}

Transverse scrapers also display large differences in the extent of retouching. Nearly $60 \%$ of transverse scrapers had a GIUR less than 0.6 , probably indicating less than $10 \%$ mass lost through retouching; but $20 \%$ of specimens had values of 1.0 , indicating they had more than $40-50 \%$ of their initial mass removed. These differences can also be illustrated using specific implements as exemplars (Figure 6.7). For instance, Figure 6.7C shows a transverse scraper made on a primary decortication flake, which has had a series of small retouch scars at the distal end. The Kuhn GIUR of 0.56 recorded for this specimen, in association with a low unretouched edge angle of $34^{\circ}$ at the distal end, is consistent with less than $10 \%$ of the original flake mass being removed by retouching. In contrast, another transverse scraper shown in Figure 6.7D had a series of large flake scars at the distal end, with retouch removing the thickest part of the flake along one half of the edge to give a GIUR of 0.91. This pattern is consistent with the removal of at least $30-35 \%$ of the original flake mass by retouching. These two illustrations exemplify the different levels of reduction present amongst transverse scrapers in this layer.

Large differences in retouch intensity between specimens classified as transverse scrapers also reflect flake characteristics: specimens with GIUR of less than 0.6 have, on average, significantly smaller platform thickness $(\mathrm{t}=2.094$, d.f. $=$ $59, \mathrm{p}=0.041)$, smaller flake thickness $(\mathrm{t}=3.616$, d.f. $=64, \mathrm{p}=0.001)$ and lower unretouched edge angles $(t=3.240$, d.f. $=64, p=0.002)$. Reduction 
intensity was therefore connected to the size and morphology of flakes, with larger flakes being more extensively retouched. However, despite the great variation in retouch between specimens in Layer 21, retouch intensity did not alter the typological status of transverse scrapers. That inference is inconsistent with the notion that transverse scrapers were once single side scrapers that had subsequently had additional retouch added to the distal end. Instead this evidence indicates that many or all transverse scrapers had always been transversely retouched, throughout their entire production and re-sharpening history.

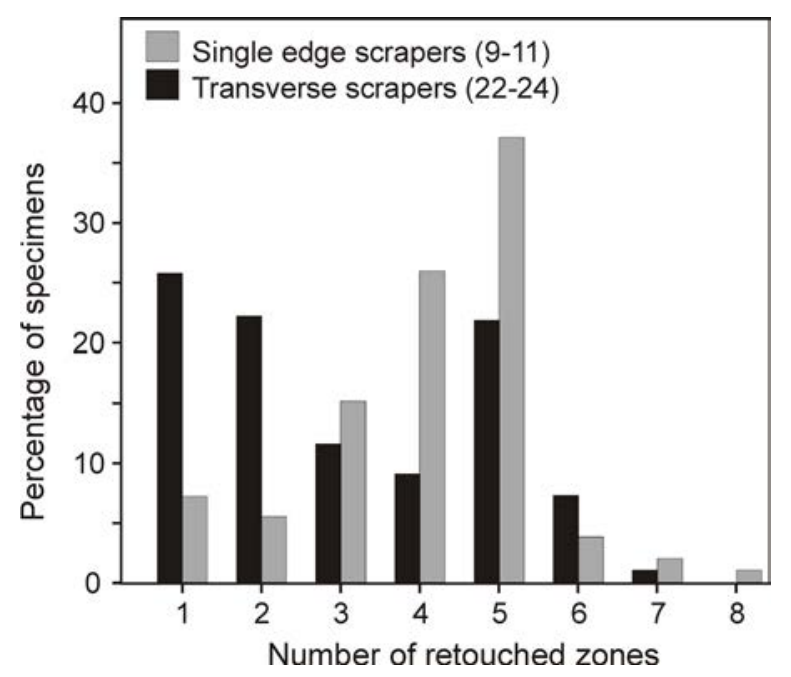

Figure 6.8: Histogram showing differences in the distribution of retouch on specimens classified as single scrapers and transverse scrapers.

Source: Author's data.

This conclusion is reinforced by information about the distribution of retouch around the perimeter of flakes (Figure 6.8). Distribution of retouch around flake perimeters is not consistent with all transverse specimens originally being single scrapers. More than $50 \%$ of transverse scrapers have retouch only toward the distal end ( $<3$ retouched zones). These specimens were never single scrapers, and we conclude that at least half the transverse scrapers began as transverse scrapers. Those with $4-6$ retouched zones may once have been single side scrapers that had retouch added to the distal end, or they may have begun as transverse scrapers that subsequently had retouch added to a lateral margin. While it is possible that in Layer 21 Dibble's hypothesised transformation of single into transverse scrapers sometimes occurred, this must have been 
infrequent compared to the common process creating transverse scrapers, in which knappers began to retouch at the distal end and continued to retouch in that location.

The initiation and maintenance of restricted patterns of retouch, at either the distal end or on a margin, probably reflects the influence of blank form. Transverse and single scrapers were regularly made on different flake blanks. For example, flakes which received retouch at their distal end (transverse scrapers) were thicker $(\mathrm{t}=1.929$, d.f. $=236, \mathrm{p}=0.055)$ and had higher unretouched edge angles $(t=2.249$, d.f. $=99, p=0.027)$ than those worked only the lateral margin. Differences in flake shape and thickness are therefore hypothesised to have been factors affecting the decision of knappers to begin working flakes laterally or distally.

\section{A retouching scheme for Layer 21}

The evidence presented here is consistent with a retouching scheme that is more elaborate and less stage-based than the one proposed by Dibble (1984, 1987b, 1995). Our interpretation of the retouching processes that created typological scraper groups in Layer 21 of Combe Grenal is represented in Figure 6.9. Most frequently, single side scrapers were retouched only on one margin for their entire history of production and maintenance. Some of those specimens were discarded after only a small amount of retouching but others were very intensively retouched on the same margin but remained, in typological terms, single scrapers. Some single side scrapers were retouched on additional margins to produce specimens classified as either double or convergent scrapers. Single scrapers were typically converted into either a double scraper or a convergent scraper, but there is little evidence for double scrapers being reworked to form convergent ones. Double and convergent scrapers have comparable levels of retouch, and are not sequential stages of retouch; they represent alternative strategies applied to single scrapers with subtly different sizes and shapes. The choice of whether to continue retouching one margin or to begin working a second, and in the latter case to retouch parallel or converging edges, appears to be related to differences in flake size and morphology. The precise interaction of blank form and retouch intensity will be pursued in future publications. 
Taxonomic Tapestries

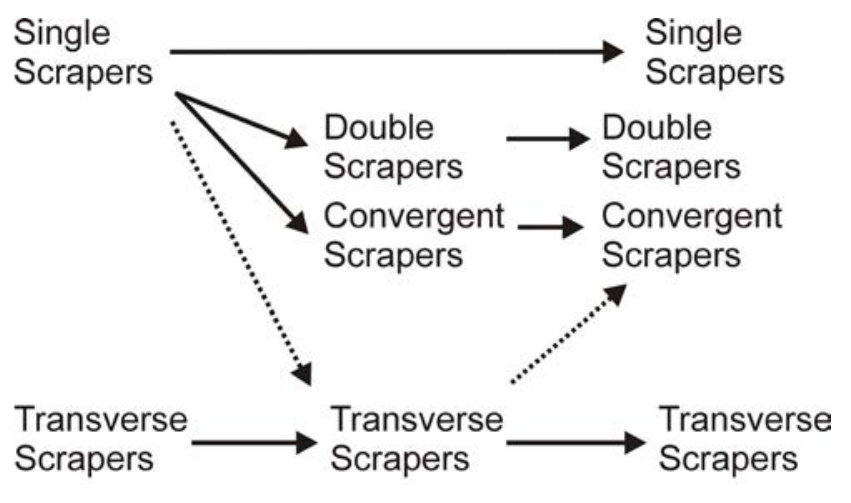

Low Amount of mass removed by retouching $\quad \mathrm{High}$

Figure 6.9: Illustration of the typological status and reduction history of flakes retouched to different degrees, using the same graphical conventions as Figure 6.1.

Source: Author's original figure.

Retouching of flakes to produce transverse scrapers appears to have been largely separate to patterns of lateral retouching leading to single, double and convergent scrapers (see Figure 6.9). Some transformations of single side scrapers to transverse scrapers, or the reworking of transverse scrapers into double/ convergent scrapers, may have occurred but in Layer 21 this was infrequent. Our interpretation of the evidence is that the majority of transverse scrapers were distally retouched throughout their 'life-span' and they had never been single side scrapers. Transverse scrapers therefore principally represent the result of a parallel pattern of production that is separate from, and constitutes an alternative to, the retouching strategy that created single side scrapers.

\section{Implications for the interpretation and analysis of Mousterian variability}

We note that while our analysis demonstrates the non-sequential structure of Quina scrapers at Combe Grenal Layer 21, and the incorrectness of Dibble's reduction model for that assemblage, the application of our analytical approach to Denticulate retouched flakes in Layers $11-12$ revealed that notched tool types did follow a sequence as predicted by the reduction model (Hiscock and Clarkson, 2007). This contrast shows that models of tool production may be correct for one site, or one level within a site, but not another, and arguments 
that one model is universally correct are not valuable. Additionally this finding reinvigorates questions of whether there is a distinct difference in tool production between Quina and Denticulate industries.

Furthermore, our interpretation of Quina scraper retouching in Layer 21 of Combe Grenal has a number of implications. Evidence presented indicates implement production was not simply a series of stages, it was multi-linear, and flake morphology was an important influence on the pattern of retouch distribution and intensity. Dibble's model of the implement classes, as stages of reduction, is not a viable depiction of the retouching technology represented in Layer 21. Our reconstruction of retouching processes conforms to many of the propositions contained in the 'blank-retouch interaction hypothesis' advocated by Turq and others.

Each of the Bordes' types examined here had multiple histories of retouching. Within each implement type some specimens received little retouch while others were intensively retouched. Perhaps retouch sometimes changed a specimen to such an extent that the type into which it would be classified was altered, but many specimens remained typologically stable even though they received additional retouch. Because different specimens belonging to each type had different histories, in particular very different amounts of retouch, the Bordes typology is not a reliable system for measuring retouch intensity. In assemblages such as this, Bordesian types tend to record the pattern and character of retouch preserved on flakes at the time they were discarded, but intensity of retouch cannot be accurately inferred from the type classification alone. Consequently, studies of spatial and temporal changes in retouch intensity will be more reliable when made on the basis of dedicated and experimentally verified systems of measurement, such as the Kuhn GIUR. In this context it is likely that robust models of land use and provisioning will not be able to be built on typological counts alone, and that long standing questions about the relationship between industrial variation and broader-scale organisational patterns can only be based on understandings of the technological processes that underpin differences in retouched flakes.

This is the first time that detailed quantitative measurements of reduction intensity have been used to assess the applicability of Dibble's 'reduction model' to Quina assemblages, and to do so by not only employing the same measures as Dibble had used but also other independent, and we argue more accurate, measurements of the retouch intensity. Our analysis reveals that the traditional typological groups are a complex product of multiple processes and not principally a signal of differing levels of retouch, even though retouch intensity is undoubtedly one of a number of factors creating morphological variation between specimens. Our conclusion that at Combe Grenal, and perhaps for many Mousterian assemblages, there is a strong interaction between 
blank and the nature of retouch which knappers applied to the blank also invites consideration of broad questions about the interpretation of implement patterns. The retouching scheme we have inferred for Layer 21 implies that sequential transformation of retouched flakes from one implement type to another was rare, and instead there were multiple, albeit branching, pathways of reduction. Demonstrating that retouching often maintained relatively stable tool forms need not indicate that Mousterian knappers had a specific design. In the instance of Combe Grenal the strong connection of retouch location, form and extent with blank form may provide a mechanism for creating regular and stable implement shapes over the reduction process, even if no well-defined, formal design was in place. Habitual application of production rules to blanks of different shapes may maintain stability in the appearance and location of a retouched edge during extended reduction. However, as Turq, Boëda and others have proposed, such production rules connecting blank form and retouching process to produce regularity in implement form might be considered a kind of design system for Middle Palaeolithic hominids. Debates of how we should think of goal-oriented behaviours in the Mousterian, and indeed the nature of technological and cogntive processes that were involved and their articulation with economic and ecological contexts, still require exploration in the quest to understand the construction of morphological diversity in Middle Palaeolithic implements. The evaluation of what constitute meaningful and valuable units of measurement, and how they may or may not be connected to traditional implement types, is not resolved; on the contrary, this discussion is merely beginning.

\section{Acknowledgements}

We offer this paper in reference to Colin Groves' significant work on classification, units of measurement, and of course hominin evolution. Both authors have enjoyed our interactions with Colin at all points through our careers, and we thank him for his support and engagement.

We acknowledge and appreciate the permission to examine the collection granted by Dr J-J Cleyet-Merle, the Director of the Musèe National de Prèhistoire des Eyzies. We thank Dr Cleyet-Merle and the Musèe National de Prèhistoire des Eyzies for providing their facilities for the prolonged duration of our project. For assistance and discussions at the Musèe National de Prèhistoire des Eyzies we thank Alain Turq, Andre Morala, and Jean-Philippe Faivre. Additionally we thank both Harold Dibble and Shannon McPherron for their advice and their generous help. A preliminary version of this paper analysing a sample of artefacts from Layer 21 was published as Hiscock and Clarkson (2008), but this paper presents an analysis of all relevant specimens from the layer and 
supersedes that earlier depiction. This research was funded by an Australian Research Council Discovery Grant (DP0451472 - A reappraisal of Western European Mousterian tools from Australian perspectives).

\section{References}

Binford LR. 1973. Interassemblage variability - the Mousterian and the 'functional' argument. In: Renfrew $\mathrm{C}$, editor. The explanation of culture change. London: Duckworth. pp. 227-254.

Binford LR. 1989. Isolating the transition to cultural adaptations: An organizational approach. In: Trinkaus, E, editor. The emergence of modern humans: Biocultural adaptations in the later Pleistocene. Cambridge: Cambridge University Press. pp. 18-41.

Binford LR, Binford SR. 1966. A preliminary analysis of functional variability in the Mousterian of Levallois Facies. Am Antiq 68:238-295.

Bisson MS. 2001. Interview with a Neanderthal: An experimental approach for reconstructing scraper production rules, and their implications for imposed form in Middle Palaeolithic tools. Cambridge Archaeol J 11:165-84.

Boëda E. 1988. Le concept laminare: Rupture et filiation avec le concept Levallois. In: Kozlowski J, editor. L'Homme Neanderthal, vol. 8, La Mutation. Liège: Etudes et Recherches Archéologique de l'Université de Liege (ERAUL). pp. $41-60$.

Bordes F. 1968. The Old Stone Age. New York: McGraw-Hill.

Bordes F. 1972. A tale of two caves. New York: Harper and Row.

Bordes F. 1961. Typologie du Paléolithique Ancien et Moyen. Mémoires de l'Institut Préhistoriques de l'Université de Bordeaux 1, Delmas: Bordeaux.

Bordes F, De Sonneville-Bordes D. 1970. The significance of variability in Palaeolithic assemblages. World Archaeol 2:61-73.

Bourguignon L. 1997. Le Moustérien de type Quina: Définition d'une nou-velle entité technique. Thèse de Doctorat de l'Université de Paris X, Nanterre.

Bourguignon L, Faivre J-P, Turq A. 2004. Ramification des chaînes opératoires: Une spécificité du Moustérien? Paléo 16:37-48. 
Clarkson C. 2002. An Index of Invasiveness for the measurement of unifacial and bifacial retouch: A theoretical, experimental and archaeological verification. J Archaeol Sci 29:65-75.

Clarkson C, Hiscock P. 2008. Tapping into the past: Exploring the extent of Palaeolithic retouching through experimentation. J Lithic Tech 33:1-15.

Close A. 1991. On the validity of Middle Paleolithic tool types: A test case from the Eastern Sahara. J Field Archaeol 18:256-264.

Debenath A, Dibble HL. 1994. Handbook of Paleolithic typology, Volume One. Lower and Middle Paleolithic of Europe. Philadelphia: University Museum, University of Pennsylvania.

Dibble HL. 1984. Interpreting typological variation of Middle Paleolithic scrapers: Function, style, or sequence of reduction? J Field Archaeol 11:431436.

Dibble HL. 1987a. Reduction sequences in the manufacture of Mousterian implements of France. In: Soffer, $\mathrm{O}$, editor. The Pleistocene Old World regional perspectives. New York: Plenum Press. pp. 33-45.

Dibble HL. 1987b. The interpretation of Middle Paleolithic scraper morphology. Am Antiq 52:109-117.

Dibble HL. 1988a. Typological aspects of reduction and intensity of utilization of lithic resources in the French Mousterian. In: Dibble H, Montet-White A, editors. Upper Pleistocene prehistory of Western Eurasia. Philadelphia: University Museum, University of Pennsylvania. pp. 181-194.

Dibble HL. 1988b. The interpretation of middle Paleolithic scraper reduction patterns. In: L'Homme de Néandertal, vol. 4, La Technique. Actes du Colloque International de Liége, L'Homme de Neandertal. pp. 49-58.

Dibble HL. 1991. Rebuttal to Close. J Field Archaeol 18:264-269.

Dibble HL. 1995. Middle Paleolithic scraper reduction: Background, clarification, and review of evidence to date. J Archaeol Meth Th 2:299-368.

Dibble HL, Rolland N. 1992. On assemblage variability in the Middle Paleolithic of Western Europe: History, perspectives, and a new synthesis. In: Dibble HL, Mellars P, editors. The Middle Paleolithic: Adaptation, behavior, and variability. Philadelphia: University Museum, University of Pennsylvania. pp. 1-28.

Gordon D. 1993. Mousterian tool selection, reduction and discard at Ghar, Israel. J Field Archaeol 20:205-218. 
Hiscock P. 1994. The end of points. In: Sullivan M, Brockwell S, Webb A, editors. Archaeology in the north. Darwin: North Australia Research Unit, The Australian National University. pp. 72-83.

Hiscock P. 2004. Slippery and Billy: Intention, selection and equifinality in lithic artefacts. Cambridge Archaeol J 14:71-77.

Hiscock P, Attenbrow V. 2005. Australia's Eastern Regional Sequence revisited: Technology and change at Capertee 3. British Archaeological Reports. International Monograph Series 1397. Oxford: Archaeopress.

Hiscock P, Clarkson C. 2005. Experimental evaluation of Kuhn's Geometric Index of Reduction and the flat-flake problem. J Archaeol Sci 32:1015-1022.

Hiscock P, Clarkson C. 2007. Retouched notches at Combe Grenal (France) and the Reduction Hypothesis. Am Antiq 72:176-190.

Hiscock P, Clarkson C. 2008. The construction of morphological diversity: A study of Mousterian implement retouching at Combe Grenal. In: Andrefsky $\mathrm{W}$, editor. Artifact life-cycle and the organization of lithic technologies. Cambridge: Cambridge University Press. pp. 106-135.

Hiscock, P, Clarkson C. 2009. The reality of reduction experiments and the GIUR: reply to Eren and Sampson. J Archaeol Sci 36:1576-1581.

Hiscock P, Turq A, Faivre J-P, Bourguignon L. 2009. Quina procurement and tool production. In: Adams B, Blades B, editors. Lithic materials and Paleolithic societies. Blackwell. pp. 232-246.

Holdaway S, Mcpherron S, Roth B. 1996. Notched tool reuse and raw material availability in French Middle Paleolithic sites. Am Antiq 61:377-387.

Kuhn S. 1990. A geometric index of reduction for unifacial stone tools. J Archaeol Sci 17:585-593.

Kuhn S. 1992. Blank morphology and reduction as determinants of Mousterian scraper morphology. Am Antiq 57:115-128.

Mellars P. 1965. Sequence and development of Mousterian traditions in southwest France. Nature 205:626-627.

Mellars P. 1986. A new chronology for the French Mousterian period. Nature 322:410-411. 
Taxonomic Tapestries

Mellars P. 1988. The chronology of the south-west French Mousterian: A review of the current debate. In: Otte M, editor. L'Homme de Néanderthal, vol. 4: La technique. Liege: Etudes et recherches Archaéologiques de l'Université de Liége. p. 97-120.

Mellars P. 1992. Technological change in the Mousterian of southwest France. In: Dibble HL, Mellars P, editors. The Middle Paleolithic: Adaptation, behavior, and variability. Philadelphia: University Museum, University of Pennsylvania. pp. 29-43.

Mellars P. 1996. The Neanderthal legacy. New York: Princeton University Press.

Rolland N. 1981. The interpretation of Middle Paleolithic variability. Man 16:15-42.

Rolland N. 1988. Observations on some Middle Paleolithic time series in southern France. In: Dibble H, Montet-White A, editors. Upper Pleistocene prehistory of Western Eurasia. University Museum Monograph 54. Philadelphia: University Museum, University of Pennsylvania. pp. 161-180.

Rolland N, Dibble HL. 1990. A new synthesis of Middle Paleolithic assemblage variability. Am Antiq 55:480-499.

Thiebaut C. 2003. L'industrie lithique de la couche III du Roc de Marsal: Le probléme de l'attribution d'une série lithique au Moustérien à Denticulés. Paléo 15:141-168.

Turq A. 1989. Approche technologique et économique du facies Moustérien de type Quina: Etude préliminaire. Bull Soc Préhist Fr 86:244-56.

Turq A. 1992. Raw material and technological studies of the Quina Mousterian in Perigord. In: Dibble HL, Mellars P, editors. The Middle Paleolithic: Adaptation, behavior, and variability. Philadelphia: University Museum, University of Pennsylvania. pp. 75-85.

Turq A. 2000. Paléolithique inférieur et moyen entre Dordogne et Lot. Paléo, Supplément 2.

Verjux C. 1988. Les Denticules Mousteriens. In: L'Homme de Néandertal, vol. 4, La Technique. Actes du Colloque International de Liége, L'Homme de Neandertal. pp. 197-204.

Verjux C, Rousseau D-D. 1986. La retouche Quina: Une mise au point. Bull Soc Préhist Fr 11-12:404-415. 
This text is taken from Taxonomic Tapestries: The Threads of Evolutionary, Behavioural and Conservation Research, edited by Alison M Behie and Marc F Oxenham, published 2015 by ANU Press, The Australian National University, Canberra, Australia. 